\title{
A note on the relation between the optic disc and the blind spot'
}

RICHARD J. STANEK

UNIVERSITY OF SANTA CLARA

The optic disc is sometimes said incorrectly to lie in a position below the fovea. This misconception arises from neglecting the inversion of the retinal image. The blind spot, regarded as a position in the visual field, in fact lies below the point of fixation, but the anatomical counterpart of the blind spot, the optic disc, lies above the fovea. It is suggest$e d$ that the term optic disc be used anatomically and the term blind spot be used only to refer to an area in the visual field.

Wyburn (1964) and Neff (1936), describing Stern's work (1926), refer to the finding that the conditions for creating apparent movement result in an impression of movement across the area of the blind spot (BS). While exploring procedures for corroborating such a finding, the author discovered a basic discrepancy in his conception of the relationship of the BS in the visual field to its corresponding anatomical structure, the optic disc, i.e., the area of exit of the optic nerve, in the retina. Indeed, the same misconception appears in certain texts widely used in psychology, viz., Geldard (1953), Andreas (1960), and Kendler (1963). Consequently, it appears appropriate to point out the misconception to others who might share such a notion and who might be in a position to propagate the error.

Geldard in describing the features of the gross anatomy of the eye states that, "The other area to be noted in addition to the fovea centralis is the colliculus or optic disc, situated about $3 \mathrm{~mm}$ to the nasal side and $1 \mathrm{~mm}$ below the fovea" (1953, p. 23). Andreas is in agreement with Geldard regarding the location of the optic. disc when he states that, "The blind spot actually falls slightly below the horizontal retinal meridian" (1960, p. 235). Finally, Kendler makes the statement that, "Slightly below the fovea and to the nasal side of it is the blind spot" $(1963, p .117)$.

However, in mapping the visual field, on a plane perpendicular to the line of sight, the BS is accurately described as being located slightly below the horizontal meridian, about $1.5^{\circ}$ or more (Scott, 1957). Due to the inversion of light waves as they pass through the lens and other media and are registered on the retina, it is apparent that the optic disc, which is the anatomical "reason" for the BS in the visual field, would have to be situated above the horizontal meridian of the eye. In fact, a number of references actually so locate the optic disc. For example, Scott states that,

The position of the blind spot, somewhat below the horizontal meridian of the visual field, corresponds to a position of the optic disc slightiy above-not below as sometimes stated-the horizontal meridan of the eye. It is legitimate to infer that the position of the optic disc, when the eye is in use, is above the horizontal meridian. This is its physiological position and it may be presumed that its anatomical position is nearly the same (Scott, 1957, p. 302).

Another reference by Reed (1960) presents a diagram of the right fundus and the right visual field which clearly locates the optic disc above the horizontal meridian of the eye and the BS below the horizontal meridian of the right visual field. Gray's classic book $(1959$, p. 1108) diagrams the interior of the posterior half of the left eye, revealing the optic disc clearly above the macula lutea which, of course, contains the fovea centralis. Finally, Southall states that, "The centres of the papilla [of the optic nerve] and the macula lutea are about $4 \mathrm{~mm}$ apart, but the latter is a little lower down on the fundus so that its upper border is nearly on a level with the centre of the former" (1937, p. 22).

In addition to these textual references it is possible to demonstrate quite simply that the optic disc must be located above the horizontal meridian of the eye, i.e., above the fovea. One can employ a variation of the usual device found in many introductory psychology texts for demonstrating the lack of sensory receptors due to the existence of the optic disc in the eye. If a vertical row of dots is located to the right of a target on which the right eye fixates and the figure is adjusted for distance to demonstrate the blind spot in the visual field, it will be observed that the lower half of the vertical row of dots disappears, an experience which could only occur if the optic disc were located above the fovea. 2

In addition, the many charts of the visual field found in texts on perimetry as well as other references on the eye portray the BS as obviously below the horizontal meridian of the visual field, thus requiring that the optic disc be above the horizontal meridian of the fundus due to the inversion of the lens.

A possible explanation for this misconception might be found in diagrams of the eye presented in various texts. The usual diagram presents a horizontal section of the eye, frequently with the nasal side at the bottom of the figure. Since the optic nerve is located on the nasal side, it is drawn below the fovea centralis in the diagram. However, it may happen that the view of the eye is assumed by the reader to be a sagittal one and that consequently the optic disc is seen to fall below 
the fovea centralis. Such an assumption is consistent with a sagittal perspective of the eye. A further confounding factor might be the ambiguity of the terms, optic disc and blind spot. In some references in texts and in oral communications the terms are used interchangeably to refer to an area in the retina. For example, if an author is attempting to convey the location of an area on the retina and uses the term blind spot, his readers may be misled if they interpret the term to refer to an area in the visual field. Kendler (1963, p. 117), Andreas (1960, p. 235) and Gray (1959, p. 1109) have actually so used the term.

Finally, it might be well to conclude this note by suggesting some practices which might help to avoid misconceptions of the relation between the optic disc and the BS. Diagrams of the eye presented in texts should be clearly labelled as horizontal views. In addition, a second diagram presenting a sagittal view of the eye would help to clarify the relationships between the anatomical sites of the optic disc and the fovea centralis. The exposition of relations between the optic disc and the BS would be less ampiguous if authors were to agree on the technical meanings attaching to certain terms, e.g., one convention might be to use the term, optic disc, only in referring to an anatomical area in the retina and the term, blind spot, only in referring to an area in the visual field.

\section{References}

Andreas, B. G. Experimental psychology. New York: Wiley, 1960. Geldard, F. A. The human senses. New York: Wiley, 1953.

Gray, H. Anatomy of the human body. Edited by C. M. Goss. (27th ed.) Philadelphia: Lea, 1959.

Kendler, H. H. Basic psychology. New York: Appleton-CenturyCrofts, 1963.

Neff, W. S. A critical investigation of the visual apprehension of movement. Amer. J. Psychol., 1936, 48, 1-42.

Reed, H. The essentials of perimetry. New York: Oxford Univer. Press, 1960.

Scott, G. I. Traquair's clinical perimetry. (7th ed.) London: Henry Kimpton, 1957.

Southall, J. P. C. Introduction to physiological optics. New York: Dover, 1937.

Stern, Annie. Die wahrnehmung von Bewegungen in der Gegend des blinden flecks, Psychol. Forsch., 1926, 7, 1-15.

Wybum, G. M., Pickford, R. W., \& Hirst, R. J. Human senses and perception. London: Oliver \& Boyd, 1964.

\section{Notes}

1. The author was involved in an NSF Summer Research Program for College Teachers at the University of Michigan, Ann Arbor in the summer of 1965 during which time he came upon the "discovery" described in this note. The author would like to express his gratitude to D. J. Weintraub, Director of the program for his patient guidance and help.

2. The author is indebted to D. Krantz of the Department of Psychology, the University of Michigan, Ann Arbor for this simple and convincing demonstration. 